\title{
Adenoidectomy in Children: What Is the Evidence and What Is its Role?
}

\author{
Alexander J. Schupper ${ }^{2}$. Javan Nation ${ }^{1,2} \cdot$ Seth Pransky ${ }^{1,2}$ \\ Published online: 2 March 2018 \\ (C) Springer Science+Business Media, LLC, part of Springer Nature 2018
}

\begin{abstract}
Purpose of Review Review the current state of the adenoidectomy procedure in the pediatric population with up-to-date indications for surgery, operative techniques, adverse events, non-surgical management of adenoid hypertrophy, and future directions. Recent Findings Adenoidectomy is indicated in children for the treatment of sleep-disordered breathing, nasal airway obstruction, recurrent acute otitis media, and chronic rhinosinusitis. A new recommendation was released in 2016, not supporting adenoidectomy for a primary indication of otitis media in children under 4 years old, including those with prior tympanostomy tubes, unless a distinct indication exists such as nasal obstruction or chronic adenoiditis. Although adenotonsillectomy is the mainstay of treatment for obstructive sleep apnea (OSA), recent studies have identified that non-obese patients with moderate OSA and small tonsils have comparable benefits with adenoidectomy alone with less complications. While conventional approaches such as indirect mirror-assisted curette and suction coagulation are still utilized, direct transnasal endoscopeassisted removal of the adenoids has proven to be a safe technique, with good short- and long-term outcomes. Novel nonsurgical therapies including immunotherapy have been evaluated.

Summary Adenoidectomy is a safe procedure in the pediatric population and leads to excellent outcomes. Adverse events are rare, and hospitalization is uncommon. Children with sleep disturbance from nasal airway obstruction, ear disease, or chronic rhinosinusitis are the best operative candidates for this procedure.
\end{abstract}

Keywords Pediatric adenoidectomy $\cdot$ Pediatric tonsillectomy $\cdot$ Surgical indications $\cdot$ Surgical complications $\cdot$ Surgical technique

\section{Introduction}

Adenoidectomy is a common pediatric surgical procedure performed by otolaryngologists today [1]. The surgical indications for adenoidectomy as stated on the website of the American Academy of Otolaryngology/Head and Neck surgery as of 2017 include [2]:

1. Four or greater episodes of recurrent purulent rhinorrhea in prior 12 months in a child $<12$ years of age.

This article is part of the Topical Collection on Pediatric Otolaryngology

Javan Nation

jnation@ucsd.edu

1 Rady Children's Hospital - San Diego, 3020 Children's Way MC 5024, San Diego, CA 92123, USA

2 UC San Diego School of Medicine, San Diego, CA, USA
2. Persisting symptoms of adenoiditis after two courses of antibiotic therapy. One course of antibiotics should be with a $\beta$-lactamase stable antibiotic for at least 2 weeks.

3. Sleep disturbance with nasal airway obstruction persisting for at least 3 months.

4. Hyponasal speech.

5. Otitis media with effusion for over 3 months or associated with additional sets of tubes.

6. Dental malocclusion or orofacial growth disturbance documented by orthodontist or dentist.

7. Cardiopulmonary complications including cor pulmonale, pulmonary hypertension, and right ventricular hypertrophy associated with upper airway obstruction.

8. Otitis media with effusion (age 4 or greater).

\section{Epidemiology and Incidence}

Large variations in adenoidectomy surgical rates have been reported from different countries [3-5]. A higher incidence 
for boys than girls is described by several studies [3, 5-8]. The most common indications for adenoid surgery have been recurrent upper airway infections, acute otitis media, otitis media with effusion, and otitis and adenoid hypertrophy [6].

A 2010 US study [9] looked at the change in procedure rate over the 10-year period of 1996-2006. In 2006, the US adenoidectomy rates were 176/100,000 in children $<18$ years old. There was no significant change in rates of solitary adenoidectomy, 183/100,000 in 1996 and 176/100,000 in 2006. However, there was an increase in the rate of adenotonsillectomy from 370/100,000 children in 1996 to 687/100,000 children in 2006.

A 2016 Swedish study [10] described adenoidectomy rates of $740 / 100,000$ in children $<10$ years old, with primary adenoidectomy reaching its peak at 3 years of age. Adenoidectomy was rarely performed on patients $<1$ year old. For children under 2 years old, adenoidectomy alone was the most common surgery, compared to children over 2 years of age, with adenotonsillectomy being the most common. Finland and Belgium report highest incidence with 1290/100,000 children and 1270/100,000 children per year, respectively.

A 2017 study from Taiwan [8] reported a total of 20,599 children undergoing adenoidectomy from 1997 to 2012 (mean age, 7.4 years; $67 \%$ boys, $24.5 / 100,000$ children). The age group of 3- to 5-year-olds had the highest incidence in both genders $(p<0.001)$, with boys having higher incidence rates than girls $(p<0.001)$. An increasing trend in rates from 1997 $(14.8 / 100,000)$ to $2012(26.9 / 100,000)$ was reported $(p<0.001)$. The indication for adenoidectomy changed with surgery for sleep-disordered breathing increasing significantly from 10.1 to $35.6 \%$, and infection as an indication decreasing from 32.3 to $8.0 \%(p<0.001)$.

\section{Assessment for Adenoid Hypertrophy}

Optimal evaluation for adenoid hypertrophy is made by focused history and physical examination, as well as adenoid assessment with direct visualization or radiography. Relevant literature has concluded nasopharyngoscopy to be the gold standard in the assessment of adenoid hypertrophy [11-13]. However, lateral neck radiography has been found to still play a role in assessment, although somewhat controversial. Feres et al. [14] performed a systematic review including 11 studies analyzing the usefulness of lateral neck X-rays for determining adenoid hypertrophy. Many limitations were identified in reported study data including large variations in the radiographic and comparative flexible nasopharyngoscopy evaluation methods, as well as assessment methods that were subjective or poorly described. Despite the limitations, the authors concluded "lateral X-rays might be considered somewhat useful, even though it could not be clearly demonstrated."

\section{Adenoidectomy for SDB/OSA}

\section{Adenoidectomy Alone}

Adenotonsillectomy is the recommended procedure for childhood obstructive sleep apnea (OSA); however, with regard to whether adenoidectomy is indicated alone in cases of young patients or the lack of tonsillar hypertrophy, the main textbook of pediatric pulmonology from 2006 states both tonsils and adenoids should be removed, even when one or the other seems to be the primary culprit [15]. Compared to adenoidectomy, tonsillectomy is associated with a higher rate of complications including morbidity and mortality. Compared to adenotonsillectomy, adenoidectomy alone complications are infrequent and associated with decreased postoperative pain, dehydration, post-operative bleeding, hospitalizations or shorter hospitalizations, and lower cost [16].

An Israeli study published in 2016 [17] studied whether adenoidectomy alone is a reasonable and appropriate treatment for children with OSA. The study included 515 children with OSA and AHI > 5, who underwent adenoidectomy or adenotonsillectomy. Patients were reevaluated on average 41 months after surgery using the Pediatric Sleep Questionnaire. The results were similar for adenoidectomy and adenotonsillectomy in non-obese children with an apnea-hypopnea index $<10$ and small tonsils $(<3)$. However, the "adenoidectomy only" group had a higher failure rate in children with severe OSA and tonsil size $\geq 3$. The authors concluded that in children under 7 years old who are non-obese with moderate OSA and small tonsils, long-term outcomes of adenoidectomy are comparable to those of adenotonsillectomy, and adenoidectomy alone is a reasonable treatment option.

\section{Adenotonsillectomy Evidence}

OSA is a common condition in children that affects $1-3 \%$ of the general pediatric population [18] and is associated with numerous adverse health outcomes. The most common identified risk factor for OSA is adenotonsillar hypertrophy, and the primary treatment is adenotonsillectomy, which accounts for more than 500,000 procedures annually in the USA alone [19]. Both the American Academy of Pediatrics and American Academy of Otolaryngology-Head and Neck Surgery recommend adenotonsillectomy as the preferred treatment for obstructive sleep apnea in children over the age of two [20•, 21]. As adenotonsillectomy is the recommendation for OSA, in the literature, it can be difficult separating out adenoidectomy evidence from adenotonsillectomy evidence. 
While tonsillectomy and adenoidectomy remain first-line therapies for OSA and hypopnea syndrome in children, the success rates for OSA resolution with adenotonsillectomy are variable. A meta-analysis of 23 studies found that the treatment success rate was 58\% [22]. Bhattacharjee et al. [23] performed a large multicenter study and found $27 \%$ of children achieved OSA cure, defined as an AHI less than 1 event per hour, following adenotonsillectomy. Residual OSA was associated with children who were older, obese, or who had more severe baseline disease. The Childhood Adenotonsillectomy Trial (CHAT) [24•] is the first randomized clinical trial of adenotonsillectomy vs watchful waiting for children with OSA. A successful outcome for adenotonsillectomy, defined as AHI less than two events per hour and an obstructive apnea index less than one event per hour, was found to be $79 \%$. Risk factors for post-operative OSA were obesity, African American race, and an AHI greater than 4.7 events per hour. Interestingly, $47 \%$ of children in the watchful waiting group had spontaneous resolution of their OSA at 7 months. However, a significant advantage for adenotonsillectomy over watchful waiting was reported for normalization of sleep study results, scores on multiple parent-reported behavioral scales, scores on SDB rating scales, and quality of life. In contrast, there were no differences in formally assessed neurocognitive attention and executive function; results of teacher-reported behavior scales were mixed.

\section{Drug-Induced Sleep Endoscopy}

Drug-induced sleep endoscopy (DISE) is a comprehensive technique for airway assessment that includes evaluation of the adenoids along with the palate, oropharynx, hypopharynx, and larynx. This assessment is directed for children with OSA of unclear etiology and often leads to complex multilevel management of the breathing disorder. Using the DISE findings to guide surgical decision making has been extensively studied recently as an alternative tool in the surgical management for OSA.

The advantage of DISE over awake physical examination is that it allows dynamic visualization of the nasopharyngeal, oropharyngeal, hypopharyngeal, and laryngeal airway during "sleep" [25]. However, in the majority of OSA cases where there are hypertrophied tonsillar and adenoidal tissues, DISE is not needed in the surgical decision-making process. The role of DISE is in cases without hypertrophied tonsils or adenoids, or in the cases where the OSA is refractory to adenotonsillectomy [26].

A recent study from Cincinnati Children's looked at the effectiveness of pediatric DISE-directed surgery for children with infant OSA or refractory OSA after adenotonsillectomy. The most commonly performed surgical procedures were adenoidectomy $(48 \%, n=27)$, supraglottoplasty $(38 \%, n=$ $21)$, tonsillectomy $(27 \%, n=15)$, lingual tonsillectomy $(13 \%, n=7)$, nasal surgery $(11 \%, n=6)$, pharyngoplasty $(7 \%, n=4)$, and partial midline glossectomy $(7 \%, n=4)$. With DISE-directed surgery, mean oAHI improved from $14.9 \pm 13.5$ to $10.3 \pm 16.2$ events $/$ h, with $54 \%$ (30 of 56 ) of children with oAHI $<5$ and $16.1 \%$ (9 of 56) with oAHI $<1$ [27].

Another recent study aimed to investigate whether DISE changes treatment decisions and outcomes in otherwise healthy children and infants with OSA. DISE altered the therapeutic decision-making in up to $1 / 3$ to $1 / 4$ who did not undergo T\&A, instead undergoing isolated adenoidectomy, tonsillectomy, or non-surgical treatment. The authors concluded that DISE provides effective, individually tailored treatment of OSA in otherwise healthy infants and children and resulted in comparable treatment outcomes when compared to standard treatment with T\&A [28].

\section{Adenoidectomy for Ear Disease}

Additional indications for adenoidectomy are ear disease including bilateral otitis media with effusion, recurrent acute otitis media ( 3 infections in 6 months or 4 in 12 months), and eustachian tube dysfunction. The benefits of adenoidectomy for otitis media are to reduce time with middle ear effusion, recurrent disease after tube extrusion, and need for repeat tube placement. Contrary to previous thoughts, the ability of adenoidectomy to improve otitis media with effusion is related to decreased bacterial load in the nasopharynx and seems to be independent of adenoidal volume.

In 2014, Wallace et al. [29] performed a review of randomized trials and reported that adenoidectomy increased otitis media with effusion resolution by $27 \%$ at 6 months (measured by otoscopy) and $22 \%$ at 6 months and $29 \%$ at 12 months (measured by tympanometry). A systematic review and metaanalysis was done by Mikals and Brigger in 2014 [30•]. Fifteen randomized trials and observational studies of tympanostomy tubes, with or without adenoidectomy, as primary therapy for acute otitis media and otitis media with effusion were reviewed. For children $\geq 4$ years old, adenoidectomy reduced the rate of repeat tympanostomy tube insertion from 36 to $17 \%$. However, no significant effect was found in children under 4 years old.

Boonacker et al. [31] performed a meta-analysis based on 1761 children nine randomized trial comparing adenoidectomy with or without tubes to no surgery or tubes alone. There was no clinical benefit in performing an adenoidectomy in children under 4 . Children ages 4 years and older spent 50 fewer days with otitis media with effusion (OME) over the next 12 months had lower failure rates (51 vs $70 \%$ ), and a lower rate of future surgery (2 vs 19\%). 
As a result of these studies, a new recommendation not supporting adenoidectomy for a primary indication of otitis media in children under 4 years old was released by the joint committee of the American Academy of OtolaryngologyHead and Neck Surgery Foundation, the American Academy of Pediatrics, and the American Academy of Family Physicians [32]. This includes those with prior tympanostomy tubes, unless a distinct indication exists such as nasal obstruction or chronic adenoiditis.

\section{Adenoidectomy for Pediatric Chronic Rhinosinusitis}

Pediatric chronic rhinosinusitis (PCRS) is defined as at least 90 continuous days of two or more symptoms of purulent rhinorrhea, nasal obstruction, facial pressure/pain, or cough. Additionally, there must be either endoscopic signs of mucosal edema, purulent drainage, or nasal polyposis and/or CT scan changes showing mucosal changes within the ostiomeatal complex and/or sinuses to make the diagnosis [33]. It is a common yet difficult problem in the pediatric population, and most patients respond to first-line medical therapy, which includes nasal saline irrigations, nasal steroid sprays, and an antibiotic directed at the most common sinonasal pathogens. Removing children from a daycare setting is effective in decreasing exposure to upper respiratory pathogens and decreasing sinusitis disease burden. The role of adenoidectomy in the treatment of refractory PCRS is supported by the literature.

The adenoid has been implicated in sinus disease, because it harbors bacteria within biofilms. Coticchia et al. [34] compared adenoid tissue removed for PCRS vs SDB for surface area coverage of biofilms. They found $94.9 \%$ of the surface area of adenoid tissue removed for PCRS had mature biofilms vs $1.9 \%$ in patients with SDB. The authors concluded that recurrent symptoms of CRS despite medical therapy are secondary to biofilm presence, and mechanical debridement of the adenoid tissue is the best therapeutic option to eradicate the biofilms.

A retrospective chart review was performed by Shin et al. [35] studying pediatric CRS and adenoid size and bacteriology. The severity of sinus disease as seen on Waters' view was correlated with the rate of bacterial isolation from the adenoid cultures $(p<0.001)$. Bacteria were isolated from $79.3 \%$ of the specimens, and in patients who grew $\mathrm{H}$. influenzae and $\mathrm{S}$. pneumoniae, there was a statistically significant increase in the preoperative radiographic sinus disease severity. In contrast, there was no correlation between adenoid size and severity of sinus disease, suggesting that the adenoid acts as a reservoir for bacteria rather than a source of obstruction.

A meta-analysis was performed studying the clinical outcome of pediatric patients undergoing adenoidectomy for refractory rhinosinusitis, with caregiver reports of symptom improvement as the main outcome measure. The summary estimate of patients who symptomatically improved following adenoidectomy was $83.4 \%$ (95\% CI $574.5-92.2 \%, p<0.001$ ), and the authors strongly suggest adenoidectomy as the firstline surgical management of refractory pediatric CRS [36].

In 2014, the AAO/HNS released a clinical consensus statement on PCRS [33]. In regard to adenoidectomy for PCRS, the following four statements reached consensus:

1. Adenoidectomy is an effective first-line surgical procedure for children up to 12 years of age with chronic rhinosinusitis.

2. Adenoidectomy can have a beneficial effect in patients with pediatric chronic rhinosinusitis that is independent of endoscopic sinus surgery.

3. Tonsillectomy (without adenoidectomy) is ineffective treatment for chronic rhinosinusitis.

\section{Surgical Technique}

An adenoidectomy can be performed by a variety of surgical techniques. The conventional adenoidectomy technique is performed via curettage, which is still used by many surgeons although decreasing as more surgeons adopt suction cautery and microdebrider adenoidectomy. Another common technique is removing the adenoid tissue using a suction cautery instrument to ablate and suction away the lymphoid tissue. A more recent technique is mirror- or endoscopic-assisted adenoidectomy by microdebrider. The microdebrider is a powered cutting device that precisely removes tissue while avoiding inadvertent mucosal trauma. The term "powered instrumentation" refers to motor-driven tools that deliver continuous suction and cutting. The main benefit of microdebrider adenoidectomy is its ability to provide precise, rapid, and complete removal of the adenoid tissue in a safe manner, without injury to the pharyngobasilar fascia.

Anand et al. [37] performed a study in 2013 comparing the curette and microdebrider techniques. The authors concluded that the surgical technique used can have considerable influence on the duration of surgery, intra-operative bleeding, postoperative pain, recovery time, and completeness of removal of the adenoid tissue.

In recent years, the endoscope-assisted approach has been heavily studied in the context of adenoidectomy. This is a technique where the endoscope is placed into the nose allowing transnasal visualization of the nasopharynx, and the adenoid is removed either transorally (used most frequently) or transnasally. It has been identified that transnasal endoscopy with conventional curette is a safe and effective technique for adenoidectomy [38]. A recent study found that the 
endoscopic approach is superior with regard to decreased operative time, decreased blood loss, and lower rates of overall post-operative complications, in comparison to convential curretage [39]. A 2011 review of surgical techniques for a power-assisted adenoidectomy found all current technologies to be safe and effective; however, the Transoral EndonasalControlled Combined Adenoidectomy (TECCA) technique was recommended, as it was considered the most ergonomic [40].

\section{Adenoid Regrowth and Revision Adenoidectomy}

Regrowth of adenoid tissue is also a potential concern following adenoidectomy. In a large study of over 10,000 adenoidectomies, it was found that the rate of revision adenoidectomy was $1.5 \%$, and children under 5 years of age were 2.5 times more likely to have a second adenoidectomy [41]. Another study reported a revision adenoidectomy rate of $9 \%$, with a median re-operation time of 16 months following initial procedure [5].

In 2017, Huo et al. [42] performed a retrospective study looking at the relationship between allergic disease and adenoid regrowth. They found that children 36 months postadenoidectomy that had adenoid regrowth had more allergic disease and higher IgE, IL-4, and IL-5 levels than the sameaged children in control group. The Pediatric Allergic Disease Quality of Life Questionnaire scores for nasal symptoms and activity were higher in children older than 36 months in the recurrence group. A multivariate logistic regression found allergic status and low levels of FoxP3 to be independent risk factors for adenotonsillar regrowth. They concluded that allergic disease is a risk factor for adenotonsillar regrowth in children following T\&A for OSA, and the risk increases with age. Gastroesophageal reflux disease (GERD) has also been shown to significantly increase the risk of disease recurrence [6].

Wei et al. [43] studied adenoid regrowth after endoscopicassisted transoral adenoidectomy down to the pharyngobasilar fascia surface. Thirty-nine patients underwent the procedure with endoscopic guidance using a power-assisted system. Follow-up assessments were done at 18-36 months after surgery, and no regrowth was identified. The authors concluded that adenoid regrowth is rare after adenoidectomy down to the pharyngobasilar fascial surface, and this fascial level should be considered the surgical boundary for adenoidectomy.

A similar study was performed in 83 patients using endoscopic-assisted coblation removing the adenoid down to pharyngobasilar fascia. In all patients, the surgical excision extended superiorly to the periosteum over the body of sphenoid; posterolaterally to the fossa of Rosenmuller, anterolaterally to the torus tubarus, and inferiorly to Passavant's ridge.
Follow-up was done with nasal endoscopy at 1 year, and there were no occurrences of adenoid regrowth [44].

Sapthevee et al. [45] performed a study looking at adenoid regrowth and adenoidectomy technique. Patients were divided into two groups based on whether their adenoidectomy was done with a microdebrider or suction coagulation. There was a revision rate of $0.84 \%$ (34 patients) for the microdebrider group and $1.5 \%$ (50 patients) for the suction coagulation group. The authors concluded that incidence of regrowth likely relates to variables other than the technique used, as there was no difference in the regrowth rate.

For patients with palatal dysfunction and marked adenoidal hypertrophy, most commonly involving children with a cleft palate, partial adenoidectomy is the preferred approach to treat the obstructive process. This technique which preserves the retropalatal adenoid alleviates the obstruction while preserving the velopharyngeal valve function. Studies have looked at various tools to maximize safety and effectiveness of partial adenoidectomy in these children who carry an increased risk for surgical complications. Previous studies have looked at methods such as suction diathermy [46] and endoscopic power-assisted microdebrider [47]. The endoscopic approach for partial adenoidectomy has also been studied, and has been found to be a safe and effective procedure, without increased risk for velopharyngeal insufficiency [48, 49]. However, when performing an adenoidectomy in a patient with a cleft palate repair, careful decision-making and an informed discussion with the patient and family is important, as these patients are high risk for post-operative complications.

\section{Adenoidectomy Complications}

Several adverse events following adenoidectomy have been studied to assess the safety of this procedure. In general, adenoidectomy in children is well tolerated with low rates of complications. There is a small risk of hemorrhage, which has been separated into primary (within the first $24 \mathrm{~h}$ following surgery) and secondary (over $24 \mathrm{~h}$ post-surgery) hemorrhage. Primary hemorrhage has a risk of approximately $0.5-0.8 \%$, and there is minimal risk of secondary hemorrhage $[5,50,51]$. The risk of primary hemorrhage in each procedure appears to be additive, as adenotonsillectomy carries double the risk as one of the procedures performed alone [51]. Interestingly, children with OSA carry higher rates of respiratory compromise postoperatively, but lower rates of postoperative bleeding [52].

Velopharyngeal insufficiency (VPI), or the dysfunction of the velopharyngeal sphincter from separating the nasal and oral cavities, is a rare but known complication that occurs in conjunction with adenoidectomy. It often manifests as hypernasality, poor speech output, and nasal regurgitation. Unlike VPI due to anatomical abnormalities such as cleft 
palate, VPI following adenoidectomy is usually transient and resolves without further surgical intervention [53]. Cephalometry may be a useful way of providing information on VPI, as it can help indicate which children have VPI, and postoperatively which children will have prolonged postoperative VPI [54, 55].

Non-traumatic atlantoaxial rotary subluxation, also known as Grisel syndrome, has previously been described in the literature, and children with Down syndrome are at higher risk for this, as they can commonly have atlantoaxial instability [56]. These children often present with torticollis and pain with rotation [57]. A corollary to this complication is pharyngobasillar fascial spasm which occurs as complication to injury and cautery to the fascial layer. This was a frequent complication with the curettage technique, but is rarely encountered with use of the microdebrider.

Nasopharyngeal stenosis is the obliteration of the normal communication between the nasopharynx and the oropharynx secondary to the fusion of the tonsillar pillars and soft palate to the posterior pharyngeal wall. This complication is very rare and is due to procedural errors of excessive excision of posterior tonsillar pillars or excessive electrocautery. Therefore, careful technique, judicious use of electrocautery, and adequate preoperative evaluation are essential in preventing nasopharyngeal stenosis. Nasopharyngeal stenosis is a very difficult complication to fix; however, palatal eversion and bilateral Z-pharyngoplasty have been shown to be effective treatments [58, 59].

In addition to the most common adenoidectomy complications, several rare complications have been recently described in the literature. In 2016, a case was published where a young girl suffered an internal carotid artery (ICA) dissection and subsequent cerebral infarction resulting in hemiplegia and global aphasia found to be due to an ICA loop later confirmed on angiogram [60]. Other very rare events described in the literature include temporomandibular joint dysfunction, vertebral osteomyelitis [58, 61, 62], and cerebrospinal fluid (CSF) leak from the use of a microdebrider leading to pneumocephalus and meningitis [63].

\section{Non-surgical Therapy for Adenoid Hypertrophy}

In previous studies, intranasal corticosteroids have been shown to significantly improve symptoms in patients with moderate to severe adenoidal hypertrophy, as well as decrease adenoid size $[64,65]$. In a 2015 review and meta-analysis of eight randomized controlled trials using mometasone for adenoid hypertrophy, it was found to be associated with improved nasal obstruction and symptoms, decreased adenoid size, and improved quality of life [66]. Fluticasone (Flonase $®$ ) has also been shown to significantly improve airway obstruction, mouth breathing, apnea, night cough, and even speech abnormalities, compared to normal saline [67]. In this study, $76 \%$ of patients who were previously recommended surgery did not require intervention. In addition to symptomatic improvement, intranasal corticosteroids have also been shown to decrease rates of surgery for adenoid hypertrophy [68]. Studies have also examined the effect of steroid nasal spray after adenoidectomy and found that administration significantly prevented regrowth and obstructive nasal symptoms if administered 3 weeks post-adenoidectomy [69]. However, these results have been controversial, as other studies have found that fluticasone is not effective in improving adenoid hypertrophy [70]. Also many of these studies have not adequately assessed the role of allergy in patients that respond to this therapy, and it is possible that improvement is from improved nasal rhinitis and not a decrease in adenoid hypertrophy.

Leukotriene inhibitors (such as Montelukast, Zafirlukast, and Pranlukast) have been studied for their role in adenoidal hypertrophy. Montelukast specifically has been shown to cause a decrease in adenoid size in $76 \%$ of patients and deemed an acceptable alternative therapy to surgical treatment [71]. In a double-blinded, placebo-controlled randomized trial, montelukast significantly improved the severity of OSA and decreased the underlying adenoid hypertrophy in children [72]. In a 2016 review of the effect of antileukotrienes in adenoid hypertrophy, it was concluded that leukotriene inhibitors reduce the apnea-hypopnea index and decrease adenotonsillar inflammation [73].

Antibiotics are generally not sufficient modes of treatment for adenoid hypertrophy, as many infections are characterized by highly resistant bacteria that do not respond to many groups of antibiotics [74, 75]. Additionally, many viruses are often associated with adenoid hypertrophy, including human bocavirus [76, 77], EBV, and polymoviruses [76].

A recent study profiling the different pathogens colonizing the adenoids and middle ear, nine respiratory viruses (rhinovirus, influenza virus, picornavirus, syncytial respiratory virus, metapneumovirus, coronavirus, enterovirus, adenovirus, and bocavirus) and five bacteria (S. pneumoniae, $\mathrm{H}$. influenzae, M. catarrhalis, $P$. aeruginosa, and $S$. aureus) were identified [78]. When children with OME were compared to controls, it was found that adenovirus was found in significantly higher rates of patients with OME than controls. Studies have identified age-specific bacteria such as Chlamydia pneumoniae in children aged $10-16$ years $[79,80]$.

\section{Genetics/Immunology}

Recently, the role of gene modification and immunomodulation in the scope of adenoid hypertrophy has been examined. Children with obstructive adenoidal hypertrophy have evidence of greater blood and urine markers of oxidative DNA damage 
compared with children without adenoid disease [81]. It has also been shown that oxidants and antioxidants play an important role in both adenotonsillar hypertrophy and chronic adenotonsillitis, but that oxidative levels differed between the two pathologies, suggesting different disease states [82].

The literature has looked into the role of the immune system in managing adenoid hypertrophy and infection, and the modulation seen with disrupting of the lymphoid tissue. The role of Th17 and Treg has been examined, and a recent study showed that as the Th17/Treg ratio increased, the size of the adenoids increased, and the ratio was significantly higher in OSA patients compared to controls [83]. Surfactant proteins, epithelial proteins modulated in the inflammatory response, have also been studied. It was found that surfactant protein (SP)-A and D were found to be downregulated in adenoid hypertrophy, and may be thought to contribute to pediatric chronic rhinosinusitis (pCRS) [84]. The immunological link between adenoid hypertrophy and otitis media with effusion has also been examined. A small study has supported the disordered interaction between CD27 and CD70 in children with adenoid hypertrophy was linked to the development of otitis media with effusion [85].

\section{Conclusion}

\section{Indications for Adenoidectomy}

While there have been many indications for adenoidectomy, sleep-disordered breathing from nasal airway obstruction, ear disease, and pediatric chronic rhinosinusitis remain the major indications for the procedure. Adenoidectomy alone is an effective treatment option in children under 7 years old who are non-obese with moderate OSA and small tonsils. There is a clinical benefit in performing an adenoidectomy in children over 4 years old at the time of tympanostomy tube placement. Adenoidectomy is over $80 \%$ effective as the first-line surgical management of refractory pediatric CRS.

\section{Adverse Events}

Adenoidectomy is a very safe procedure with the most frequent complications, albeit rare, being primary hemorrhage and velopharyngeal insufficiency.

\section{Treatment Options}

Recent literature has emphasized the use of the transnasal endoscope-assisted approach and has found that it is safe and effective, and may provide results superior to conventional operative techniques, as it can improve visualization and facilitate removal of all of the adenoid tissue down to the pharyngobasilar fascia. Specific surgical devices and approaches have additionally been studied. Non-surgical therapies include intranasal steroids and leukotriene inhibitors, while antibiotics have not been shown to be effective. New immunotherapies are currently being evaluated for their effectiveness in decreasing adenoid hypertrophy and infection.

The adenoidectomy technique has progressed from blind curette to the more refined, safer, and effective techniques of microdebrider or coblation. Removing all of the adenoid tissue, which is more easily accomplished with microdebrider and coblation, has shown to prevent adenoid recurrence. The use of transnasal endoscopy can help in removing all of the adenoid by improving visualization and has been shown to be superior to the traditional curettage technique.

\section{Compliance with Ethical Standards}

Conflicts of Interest The authors declare that they have no conflict of interest.

Human and Animal Rights and Informed Consent This article does not contain any studies with human or animal subjects performed by any of the authors.

\section{References}

Papers of particular interest, published recently, have been highlighted as:

- Of importance

1. Ingram DG, Friedman NR. Toward adenotonsillectomy in children: a review for the general pediatrician. JAMA Pediatr. 2015;169(12): 1155-61. https://doi.org/10.1001/jamapediatrics.2015.2016.

2. AAO/HNS Clinical Indicators: Adenoidectomy Available at: https:// higherlogicdownload.s3-external-1.amazonaws.com/ENTNET/ Adenoidectomy-CI Updated.pdf?AWSAccessKeyId= AKIAJH5D4I4FWRALBOUA\&Expires $=1504509869 \&$ Signature $=$ 8MwBTzlygBOHcHM6auKZO2CA6oo\%3D.

3. Haapkyla J, Karevold G, Kvaerner KJ, Pitkaranta A. Trends in otitis media surgery: a decrease in adenoidectomy. Int J Pediatr Otorhinolaryngol. 2008;72(8):1207-13. https://doi.org/10.1016/j. ijporl.2008.04.012.

4. Schilder AG, Lok W, Rovers MM. International perspectives on management of acute otitis media: a qualitative review. Int $\mathrm{J}$ Pediatr Otorhinolaryngol. 2004;68(1):29-36. https://doi.org/10. 1016/j.ijporl.2003.09.002.

5. Thomas K, Boeger D, Buentzel J, et al. Pediatric adenoidectomy: a population-based regional study on epidemiology and outcome. Int J Pediatr Otorhinolaryngol. 2013;77(10):1716-20. https://doi.org/ 10.1016/j.ijporl.2013.07.032.

6. Dearking AC, Lahr BD, Kuchena A, Orvidas LJ. Factors associated with revision adenoidectomy. Otolaryngol Head Neck Surg. 2012;146(6):984-90. https://doi.org/10.1177/0194599811435971.

7. van den Aardweg MT, Rovers MM, Kraal A, Schilder AG. Current indications for adenoidectomy in a sample of children in the Netherlands. B-ent. 2010;6(1):15-8.

8. Lee C-H, Hsu W-C, Ko J-Y, Yeh T-H, Chang W-H, Kang K-T.

9. Bhattacharyya N, Lin HW. Changes and consistencies in the epidemiology of pediatric adenotonsillar surgery, 1996-2006. 
Otolaryngol Head Neck Surg. 2010;143(5):680-4. https://doi.org/ 10.1016/j.otohns.2010.06.918.

10. Gerhardsson H, Stalfors J, Odhagen E, Sunnergren O. Pediatric adenoid surgery in Sweden 2004-2013: incidence, indications and concomitant surgical procedures. Int $\mathrm{J}$ Pediatr Otorhinolaryngol. 2016;87:61-6. https://doi.org/10.1016/j.ijporl. 2016.05.020.

11. Bitar MA, Birjawi G, Youssef M, Fuleihan N. How frequent is adenoid obstruction? Impact on the diagnostic approach. Pediatr Int. 2009;51(4):478-83. https://doi.org/10.1111/j.1442-200X. 2008.02787.x.

12. Kubba H, Bingham BJ. Endoscopy in the assessment of children with nasal obstruction. J Laryngol Otol. 2001;115(5):380-4.

13. Mlynarek A, Tewfik MA, Hagr A, et al. Lateral neck radiography versus direct video rhinoscopy in assessing adenoid size. J Otolaryngol. 2004;33(06):360-5. https://doi.org/10.2310/7070. 2004.03074.

14. Feres MF, Hermann JS, Cappellette M Jr, Pignatari SS. Lateral Xray view of the skull for the diagnosis of adenoid hypertrophy: a systematic review. Int J Pediatr Otorhinolaryngol. 2011;75(1):1-11. https://doi.org/10.1016/j.ijporl.2010.11.002.

15. Gozal D KL. Disorders of breathing during sleep. In: Chernick V, Boat TF, Wilmott RW, Bush A, eds. Kendig's Disorder of the respiratory tract in children. Elsevier Saunders, 2006.

16. Randall DA, Hoffer ME. Complications of tonsillectomy and adenoidectomy. Otolaryngol Head Neck Surg. 1998;118(1):61-8. https://doi.org/10.1016/S0194-5998(98)70376-6.

17. Domany KA, Dana E, Tauman R, et al. Adenoidectomy for obstructive sleep apnea in children. J Clin Sleep Med. 2016;12(09):128591. https://doi.org/10.5664/jcsm.6134.

18. Bodenner KA, Jambhekar SK, Com G, Ward WL. Assessment and treatment of obstructive sleep-disordered breathing. Clin Pediatr (Phila). 2014;53(6):544-8. https://doi.org/10.1177/ 0009922814527501.

19. Bhattacharyya N, Lin HW.

20. Marcus CL, Brooks LJ, Draper KA, et al. Diagnosis and management of childhood obstructive sleep apnea syndrome. Pediatrics. 2012;130:576-84. The revised clinical practice guideline with up-to-date recommendations for the diagnosis and management of the obstructive sleep apnea syndrome in children and adolescents.

21. Baugh RF, Archer SM, Mitchell RB, et al. Clinical practice guideline: tonsillectomy in children. Otolaryngol Head Neck Surg. 2011;144(1_supp1):S1-30. https://doi.org/10.1177/ 0194599810389949.

22. Friedman M, Wilson M, Lin HC, Chang HW. Updated systematic review of tonsillectomy and adenoidectomy for treatment of pediatric obstructive sleep apnea/hypopnea syndrome. Otolaryngol Head Neck Surg. 2009;140(6):800-8. https://doi.org/10.1016/j. otohns.2009.01.043.

23. Bhattacharjee R, Kheirandish-Gozal L, Spruyt K, et al. Adenotonsillectomy outcomes in treatment of obstructive sleep apnea in children: a multicenter retrospective study. Am J Respir Crit Care Med. 2010;182(5):676-83. https://doi.org/10.1164/rccm. 200912-1930OC

24. Marcus CL, Moore RH, Rosen CL, et al. A randomized trial of adenotonsillectomy for childhood sleep apnea. N Engl J Med. 2013;368:2366-76. Important study to read and understand in detail, as this is the best study to date comparing outcomes of surgical intervention vs watchful waiting in children with OSA.

25. Viana Ada C Jr, Thuler LC, Araujo-Melo MH. Drug-induced sleep endoscopy in the identification of obstruction sites in patients with obstructive sleep apnea: a systematic review. Braz J Otorhinolaryngol. 2015;81(4):439-46. https://doi.org/10.1016/j. bjorl.2015.01.007.
26. Galluzzi F, Pignataro L, Gaini RM, Garavello W. Drug induced sleep endoscopy in the decision-making process of children with obstructive sleep apnea. Sleep Med. 2015;16(3):331-5. https://doi. org/10.1016/j.sleep.2014.10.017.

27. He S, Peddireddy NS, Smith DFet al. Outcomes of drug-induced sleep endoscopy-directed surgery for pediatric obstructive sleep apnea. Otolaryngol Head Neck Surg 2017:194599817740332.

28. Boudewyns A, Saldien V, Van de Heyning P, Verhulst S. Druginduced sedation endoscopy in surgically naive infants and children with obstructive sleep apnea: impact on treatment decision and outcome. Sleep Breath. 2017; https://doi.org/10.1007/s11325-0171581-7.

29. Wallace IF, Berkman ND, Lohr KN, Harrison MF, Kimple AJ, Steiner MJ. Surgical treatments for otitis media with effusion: a systematic review. Pediatrics. 2014;133(2):296-311. https://doi. org/10.1542/peds.2013-3228.

30. Mikals SJ, Brigger MT. Adenoidectomy as an adjuvant to primary tympanostomy tube placement: a systematic review and meta-analysis. JAMA Otolaryngol Head Neck Surg. 2014;140:95-101. Good study to read as it identified that adenoidectomy $\geq 4$ years old reduced the rate of repeat tympanostomy tube insertion. However, no significant effect was found in children under 4 years old. As a result, adenoidectomy is no longer recommended for repeat tympanostomy tube placement in children under 4 years old with no nasal symptoms, which is a change from earlier recommendations.

31. Boonacker CW, Rovers MM, Browning GG, Hoes AW, Schilder AG, Burton MJ. Adenoidectomy with or without grommets for children with otitis media: an individual patient data meta-analysis. Health Technol Assess. 2014;18(5):1-118. https://doi.org/10.3310/ hta18050.

32. Rosenfeld RM, Shin JJ, Schwartz SR, et al. Clinical practice guideline: otitis media with effusion executive summary (update). Otolaryngol Head Neck Surg. 2016;154(2):201-14. https://doi. org/10.1177/0194599815624407.

33. Brietzke SE, Shin JJ, Choi S, et al. Clinical consensus statement: pediatric chronic rhinosinusitis. Otolaryngol Head Neck Surg. 2014;151(4):542-53. https://doi.org/10.1177/0194599814549302.

34. Coticchia J, Zuliani G, Coleman C, et al. Biofilm surface area in the pediatric nasopharynx: chronic rhinosinusitis vs obstructive sleep apnea. Arch Otolaryngol Head Neck Surg. 2007;133(2):110-4. https://doi.org/10.1001/archotol.133.2.110.

35. Shin KS, Cho SH, Kim KR, et al. The role of adenoids in pediatric rhinosinusitis. Int J Pediatr Otorhinolaryngol. 2008;72(11):164350. https://doi.org/10.1016/j.ijporl.2008.07.016.

36. Brietzke SE, Brigger MT. Adenoidectomy outcomes in pediatric rhinosinusitis: a meta-analysis. Int J Pediatr Otorhinolaryngol. 2008;72(10):1541-5. https://doi.org/10.1016/j.ijporl.2008.07.008.

37. Anand V, Sarin V, Singh B. Changing trends in adenoidectomy. Indian J Otolaryngol Head Neck Surg. 2014;66(4):375-80. https://doi.org/10.1007/s12070-013-0698-7.

38. Das AT, Prakash SB, Priyadarshini V. Combined conventional and endoscopic microdebrider-assisted adenoidectomy: a tertiary centre experience. J Clin Diagn Res. 2017;11:Mc05-mc07.

39. Yang L, Shan Y, Wang S, Cai C, Zhang H. Endoscopic assisted adenoidectomy versus conventional curettage adenoidectomy: a meta-analysis of randomized controlled trials. Spring. 2016;5(1): 426. https://doi.org/10.1186/s40064-016-2072-1.

40. Pagella F, Pusateri A, Canzi P, et al. The evolution of the adenoidectomy: analysis of different power-assisted techniques. Int J Immunopathol Pharmacol. 2011;24(4 suppl):55-9. https:// doi.org/10.1177/03946320110240S411.

41. Duval M, Chung JC, Vaccani JP. A case-control study of repeated adenoidectomy in children. JAMA Otolaryngol Head Neck Surg. 2013;139(1):32-6. https://doi.org/10.1001/jamaoto.2013.1060. 
42. Huo Z, Shi J, Shu Y, Xiang M, Lu J, Wu H. The relationship between allergic status and adenotonsillar regrowth: a retrospective research on children after adenotonsillectomy. Sci Rep. 2017;7: 46615. https://doi.org/10.1038/srep46615.

43. Wei L, Wang M, Hua N, Tong K, Zhai L, Wang Z. Regrowth of the adenoids after adenoidectomy down to the pharyngobasilar fascial surface. J Laryngol Otol. 2015;129(07):662-5. https://doi.org/10. 1017/S0022215115001437.

44. Agrawal V, Agarwal PK, Agrawal A. Defining the surgical limits of adenoidectomy so as to prevent recurrence of adenoids. Indian $\mathrm{J}$ Otolaryngol Head Neck Surg. 2016;68(2):131-4. https://doi.org/ 10.1007/s12070-016-0971-7.

45. Sapthavee A, Bhushan B, Penn E, Billings KR. A comparison of revision adenoidectomy rates based on techniques. Otolaryngol Head Neck Surg. 2013;148(5):841-6. https://doi.org/10.1177/ 0194599813477830.

46. Tweedie DJ, Skilbeck CJ, Wyatt ME, Cochrane LA. Partial adenoidectomy by suction diathermy in children with cleft palate, to avoid velopharyngeal insufficiency. Int J Pediatr Otorhinolaryngol. 2009;73(11):1594-7. https://doi.org/10.1016/j. ijporl.2009.08.014.

47. Askar SM, Quriba AS. Powered instrumentation for transnasal endoscopic partial adenoidectomy in children with submucosal cleft palate. Int J Pediatr Otorhinolaryngol. 2014;78(2):317-22. https:// doi.org/10.1016/j.ijporl.2013.11.033.

48. Finkelstein Y, Wexler DB, Nachmani A, Ophir D. Endoscopic partial adenoidectomy for children with submucous cleft palate. Cleft Palate Craniofac J. 2002;39(5):479-86. https://doi.org/10.1597/ 1545-1569(2002)039<0479:EPAFCW>2.0.CO;2.

49. Stern Y, Segal K, Yaniv E. Endoscopic adenoidectomy in children with submucosal cleft palate. Int J Pediatr Otorhinolaryngol. 2006;70(11):1871-4. https://doi.org/10.1016/j.ijporl.2006.06.013.

50. Lowe D, Brown P, Yung M. Adenoidectomy technique in the United Kingdom and postoperative hemorrhage. Otolaryngol Head Neck Surg. 2011;145(2):314-8. https://doi.org/10.1177/ 0194599811403119.

51. Tomkinson A, Harrison W, Owens D, Fishpool S, Temple M. Postoperative hemorrhage following adenoidectomy. Laryngoscope. 2012;122(6):1246-53. https://doi.org/10.1002/lary. 23279.

52. De Luca Canto G, Pacheco-Pereira C, Aydinoz S, et al. Adenotonsillectomy complications: a meta-analysis. Pediatrics. 2015;136(4):702-18. https://doi.org/10.1542/peds.2015-1283.

53. Khami M, Tan S, Glicksman JT, Husein M. Incidence and risk factors of velopharyngeal insufficiency postadenotonsillectomy. Otolaryngol Head Neck Surg. 2015;153(6):1051-5. https://doi. org/10.1177/0194599815596494.

54. Kassem F, Ebner Y, Nageris B, Watted N, DeRowe A, Nachmani A. Cephalometric findings among children with velopharyngeal dysfunction following adenoidectomy-a retrospective study. Clin Otolaryngol. 2017;42(6):1289-94. https://doi.org/10.1111/coa. 12875.

55. Veerapandiyan A, Blalock D, Ghosh S, Ip E, Barnes C, Shashi V. The role of cephalometry in assessing velopharyngeal dysfunction in velocardiofacial syndrome. Laryngoscope. 2011;121(4):732-7. https://doi.org/10.1002/lary.21449.

56. Gross IT, Bahar-Posey L. Atlanto-axial subluxation after adenoidectomy. Pediatr Emerg Care. 2017;33(6):416-7. https:// doi.org/10.1097/PEC.0000000000001154.

57. Spennato P, Nicosia G, Rapana Aet al. Grisel syndrome following adenoidectomy: surgical management in a case with delayed diagnosis. World Neurosurg 2015; 84:1494.e1497-1412.

58. Wan DC, Kumar A, Head CS, Katchikian H, Bradley JP. Amelioration of acquired nasopharyngeal stenosis, with bilateral Z-pharyngoplasty. Ann Plast Surg. 2010;64(6):747-50. https:// doi.org/10.1097/SAP.0b013e3181a73009.
59. Abdel-Fattah G. Palatal eversion: a new technique in treatment of nasopharyngeal stenosis. Int J Pediatr Otorhinolaryngol. 2012;76(6):879-82. https://doi.org/10.1016/j.ijporl.2012.02.064.

60. Garg A, Singh Y, Singh P, Goel G, Bhuyan S. Carotid artery dissection following adenoidectomy. Int J Pediatr Otorhinolaryngol. 2016;82:98-101. https://doi.org/10.1016/j.ijporl.2015.12.017.

61. Baker LL, Bower CM, Glasier CM. Atlanto-axial subluxation and cervical osteomyelitis: two unusual complications of adenoidectomy. Ann Otol Rhinol Laryngol. 1996;105(4):295-9. https://doi.org/10.1177/000348949610500410.

62. Mathew R, Asimacopoulos E, Walker D, Gutierrez T, Valentine P, Pitkin L. Analysis of clinical negligence claims following tonsillectomy in England 1995 to 2010. Ann Otol Rhinol Laryngol. 2012;121(5):337-40. https://doi.org/10.1177/ 000348941212100509 .

63. Moreno-Luna R, Cardenas Ruiz-Valdepenas E, Tato JI, RiveroGarvia M, Marquez-Rivas J, Mochon Martin A. Basiespinal cerebrospinal fluid leak as a complication after adenoidectomy: case report and literature review. World Neurosurg 2016; 93:484.e489_ 484.e412.

64. Chadha NK, Zhang L, Mendoza-Sassi RA, Cesar JA. Using nasal steroids to treat nasal obstruction caused by adenoid hypertrophy: does it work? Otolaryngol Head Neck Surg. 2009;140(2):139-47. https://doi.org/10.1016/j.otohns.2008.11.008.

65. Zhang L, Mendoza-Sassi RA, Cesar JA, Chadha NK. Intranasal corticosteroids for nasal airway obstruction in children with moderate to severe adenoidal hypertrophy. Cochrane Database Syst Rev 2008:Cd006286.

66. Chohan A, Lal A, Chohan K, Chakravarti A, Gomber S. Systematic review and meta-analysis of randomized controlled trials on the role of mometasone in adenoid hypertrophy in children. Int J Pediatr Otorhinolaryngol. 2015;79(10):1599-608. https://doi.org/10.1016/ j.ijporl.2015.07.009.

67. Demirhan H, Aksoy F, Ozturan O, Yildirim YS, Veyseller B. Medical treatment of adenoid hypertrophy with "fluticasone propionate nasal drops". Int J Pediatr Otorhinolaryngol. 2010;74(7): 773-6. https://doi.org/10.1016/j.ijporl.2010.03.051.

68. Sakarya EU, Bayar Muluk N, Sakalar EG, et al. Use of intranasal corticosteroids in adenotonsillar hypertrophy. J Laryngol Otol. 2017;131(05):384-90. https://doi.org/10.1017/ S0022215117000408.

69. Yildirim YS, Senturk E, Eren SB, Dogan R, Tugrul S, Ozturan O. Efficacy of nasal corticosteroid in preventing regrowth after adenoidectomy. Auris Nasus Larynx. 2016;43(6):637-40. https:// doi.org/10.1016/j.anl.2016.02.001.

70. Jazi SM, Barati B, Kheradmand A. Treatment of adenotonsillar hypertrophy: a prospective randomized trial comparing azithromycin vs. fluticasone. J Res Med Sci. 2011;16(12):1590-7.

71. Shokouhi F, Meymaneh Jahromi A, Majidi MR, Salehi M. Montelukast in adenoid hypertrophy: its effect on size and symptoms. Iran J Otorhinolaryngol. 2015;27(83):443-8.

72. Goldbart AD, Greenberg-Dotan S, Tal A. Montelukast for children with obstructive sleep apnea: a double-blind, placebo-controlled study. Pediatrics. 2012;130(3):e575-80. https://doi.org/10.1542/ peds.2012-0310.

73. Kar M, Altintoprak N, Muluk NB, Ulusoy S, Bafaqeeh SA, Cingi C. Antileukotrienes in adenotonsillar hypertrophy: a review of the literature. Eur Arch Otorhinolaryngol. 2016;273(12):4111-7. https://doi.org/10.1007/s00405-016-3983-8.

74. Antos-Bielska M, Lau-Dworak M, Olszewska-Sosinska O, ZielnikJurkiewicz B, Trafny EA. Utility of antimicrobial susceptibility testing of multiple Haemophilus influenzae isolates from throat swabs of children with adenoid hypertrophy. Diagn Microbiol Infect Dis. 2014;79(3):396-8. https://doi.org/10.1016/j. diagmicrobio.2014.03.013. 
75. Trafny EA, Olszewska-Sosinska O, Antos-Bielska M, et al. Carriage of antibiotic-resistant Haemophilus influenzae strains in children undergoing adenotonsillectomy. Int J Med Microbiol. 2014;304(5-6):554-64. https://doi.org/10.1016/j.ijmm.2014.03. 004.

76. Gunel C, Kirdar S, Omurlu IK, Agdas F. Detection of the EpsteinBarr virus, human bocavirus and novel $\mathrm{KI}$ and $\mathrm{KU}$ polyomaviruses in adenotonsillar tissues. Int J Pediatr Otorhinolaryngol. 2015;79(3):423-7. https://doi.org/10.1016/j.ijporl.2015.01.007.

77. Proenca-Modena JL, Paula FE, Buzatto GP, et al. Hypertrophic adenoid is a major infection site of human bocavirus 1 . J Clin Microbiol. 2014;52(8):3030-7. https://doi.org/10.1128/JCM. 00870-14.

78. Buzatto GP, Tamashiro E, Proenca-Modena JL, et al. The pathogens profile in children with otitis media with effusion and adenoid hypertrophy. PLoS One. 2017;12(2):e0171049. https://doi.org/10. 1371/journal.pone.0171049.

79. Bielicka A, Zielnik-Jurkiewicz B, Podsiadly E, ProchorecSobieszek M, Rogulska J, Demkow U. Role of chlamydia pneumoniae in the pathogenesis of hypertrophy and adenoid tissue inflammation in children. Otolaryngol Pol. 2016;70(5):7-12. https://doi.org/10.5604/00306657.1209437.

80. Bielicka A, Zielnik-Jurkiewicz B, Podsiadly E, Rogulska J, Demkow U. Chlamydia pneumoniae and typical bacteria occurrence in adenoid in children qualified for adenoidectomy. Int $\mathrm{J}$ Pediatr Otorhinolaryngol. 2014;78(5):828-31. https://doi.org/10. 1016/j.ijporl.2014.02.023.
81. Yoruk O, Alp H, Yuksel S, Bakan E. DNA damage in children with obstructive adenotonsillar hypertrophy. J Craniofac Surg. 2014;25(6):2156-9. https://doi.org/10.1097/SCS. 0000000000001158 .

82. Kiroglu AF, Noyan T, Oger M, Kara T. Oxidants and antioxidants in tonsillar and adenoidal tissue in chronic adenotonsillitis and adenotonsillar hypertrophy in children. Int $\mathrm{J}$ Pediatr Otorhinolaryngol. 2006;70(1):35-8. https://doi.org/10.1016/j. ijporl.2005.05.006.

83. Ni K, Zhao L, Wu J, Chen W, HongyaYang LX. Th17/Treg balance in children with obstructive sleep apnea syndrome and the relationship with allergic rhinitis. Int J Pediatr Otorhinolaryngol. 2015;79(9):1448-54. https://doi.org/10.1016/j.ijporl.2015.06.026.

84. Qu XP, Huang ZX, Sun Y, et al. Expression of innate immunity genes in epithelial cells of hypertrophic adenoids with and without pediatric chronic rhinosinusitis: a preliminary report. Chin Med J. 2015;128(21):2913-8. https://doi.org/10.4103/0366-6999.168056.

85. Ratomski K, Zelazowska-Rutkowska B, Wysocka J, Skotnicka B, Kasprzycka E, Hassmann-Poznanska E. [Expression CD27 on T and B lymphocytes in hypertrophied adenoids at children with otitis media with effusion]. Otolaryngol Pol 2009; 63:264-270, Ekspresja receptora CD27 na limfocytach T i B w tkance przerosłych migdałków gardłowych u dzieci chorych na wysiękowe zapalenie ucha środkowego, 3, DOI: https://doi.org/ 10.1016/S0030-6657(09)70120-9. 